\title{
Aplicação da técnica dos Três “L's” em ferida lacerante na face de duas potras Quarto de Milha
}

Iolanda Gea Kassem ${ }^{[]^{*}}$, Maria Inês Gay da Fonseca Aallgayer Diano[a], Julia Savietto Frati[ib], Malvina Martins Parré[c], Laura Leandra Halinski[a], Laura Blair Bailey ${ }^{[[]}$, Diego Melo Demier de Carvalho ${ }^{[e]}$, Eduardo Malschitzky ${ }^{[f]}$

\author{
[a] Therapy4Horses, Purcell, OK, Estados Unidos \\ [b] Universidade Paulista (UNIP), São Paulo, SP, Brasil

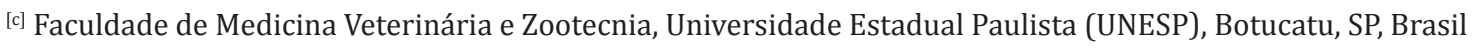 \\ [d] Texas Tech University, Lubbock, TX, Estados Unidos \\ [e] Centro Universitário Anhanguera, Niterói, RJ, Brasil \\ [f] Universidade Federal do Rio Grande do Sul (UFRGS), Porto Alegre, RS, Brasil
}

*Autor correspondente

e-mail: therapy4horsesestudos@gmail.com

\section{Resumo}

Feridas são frequentes no atendimento clínico de equinos e também alvos de inúmeros estudos na medicina veterinária para a elaboração de técnicas que acelerem o reparo celular e que ainda promovam uma cicatrização de boa qualidade. A associação de métodos fisioterápicos junto ao manejo clínico de feridas tem apresentado grandes vantagens. A técnica dos Três "L's" foi instituída pela Therapy4Horses, no tratamento de feridas de difícil resolução em equinos. A sigla consiste da inicial de três procedimentos que a caracterizam: low friction, lasertherapy e Leptospermum scoparium, ou seja, baixa fricção, laserterapia e pomada à base de Leptospermum scoparium. A limpeza de feridas com soluções adequadas e com baixa fricção promove a manutenção da camada mais superficial da pele, facilitando o processo cicatricial. 0 laser, com seu efeito fotobioestimulador, tem relação direta na síntese de ATP celular, na redução da inflamação e na estimulação da fase proliferativa da cicatrização. 0 metilglioxal, principal componente da pomada citada, possui propriedades anti-inflamatórias e antibacterianas potentes, comprovadas cientificamente, além de promover um ambiente adequado para a fase de reparo tecidual. Relatam-se os casos de duas potras da raça Quarto de Milha, de seis e sete meses de idade, que apresentaram uma ferida lacerante localizada na região de fronte e chanfro, com aproximadamente $12 \times 10 \mathrm{~cm}$ e $41 \times 20 \mathrm{~cm}$ de comprimento e largura, respectivamente. Além do alto grau de contaminação, as feridas apresentavam aspecto necrótico e exposição óssea. A paciente com a lesão de menor extensão ainda apresentava sinais clínicos de rodococose e 
leucocitose nos exames laboratoriais e, portanto, foram administrados antibióticos (Claritromicina - 750mg, Rifampicina - 500mg, BID, por 21 dias), protetor gástrico (Gastroguard ${ }^{\circledR}$ ) e probiótico (5ml, Proviable ${ }^{\circledR}$ ). Em contrapartida, a outra potra foi tratada somente com a associação de sulfadiazina e trimetoprima $(400 \mathrm{mg}$, BID, por 10 dias) pela gravidade da lesão. Mesmo com a antibioticoterapia sendo iniciada antes da aplicação da técnica dos Três "L's", não foi observado controle da infecção no local da lesão e sua progressão em relação à cicatrização era lenta. No primeiro caso, a técnica fora realizada em quatro sessões, com intervalos de 10-15 dias, e no segundo caso, nove sessões com intervalos de 3-10 dias. Em ambas as pacientes, a região era mantida fechada com bandagem aderente durante esse período. 0 manejo das feridas era iniciado pela limpeza com gaze umedecida com solução de ácido hipocloroso a $0,0120 \%$, realizada com baixa fricção, seguida pela laserterapia (laser de He-Ne, classe IIIb, $904 \mathrm{~nm}, 500 \mathrm{~mW}, 1 \mathrm{~J} / \mathrm{cm}^{2}$ ) ao longo de toda a extensão da lesão e finalizado pela aplicação da pomada à base de Leptospermum scoparium e recobrimento com gaze e bandagem elástica. Com a rápida epitelização, o recobrimento ósseo fora observado, nestes casos, a partir da segunda sessão. Após aproximadamente 33 dias do início da aplicação da técnica, as feridas se apresentavam cicatrizadas. Com isso, conclui-se que a utilização da técnica dos Três "L's" mostrou-se benéfica no reparo de feridas, promovendo um tecido cicatricial de boa qualidade e sem a ocorrência de complicações durante as terapias.

Palavras-chave: Lesão cutânea. Equino. Leptospermum scoparium. 